\title{
Pretreatmet with 5\% lidocaine patch reduces cannula-induced and propofol-induced pain: a randomized, double-blind, placebo-controlled study
} Korean Journal of Anesthesiology

\author{
Jung-Min Hong ${ }^{1,2}$, Hyeon Jeong Lee ${ }^{1,2}$, Ah Reum Cho ${ }^{1,2}$, Ji Seok Baik ${ }^{1,2}$, \\ Do Won Lee ${ }^{1,2}$, Young Tae Ji ${ }^{1}$, Ki Chan Yoo $^{1}$, and Hae-Kyu Kim ${ }^{1,2}$ \\ ${ }^{1}$ Department of Anesthesia and Pain Medicine, Pusan National University Hospital, ${ }^{2}$ Medical Research Institute, \\ Pusan National University School of Medicine, Busan, Korea
}

\begin{abstract}
Background: The purpose of this study was to determine the efficacy of 5\% lidocaine patch in reducing propofol-induced pain and cannula-induced pain.

Methods: In a randomized, double-blind study, 126 patients were divided into one of three groups: pretreatment with a 5\% lidocaine patch (Lidotop ${ }^{\circledR}$ ) and premixed $2 \mathrm{ml}$ of normal saline with $1.5 \mathrm{mg} / \mathrm{kg}$ of $1 \%$ propofol (Group A); pretreatment with a placebo patch and premixed $2 \mathrm{ml}$ of normal saline with $1.5 \mathrm{mg} / \mathrm{kg}$ of $1 \%$ propofol (Group B); or pretreatment with a placebo patch and premixed $2 \mathrm{ml}$ of $2 \%$ lidocaine $(40 \mathrm{mg}$ ) with $1.5 \mathrm{mg} / \mathrm{kg}$ of $1 \%$ propofol (Group C) for induction of anesthesia. Pain severity was evaluated on a four-point verbal rating scale during intravenous cannulation, propofol injection, and $24 \mathrm{~h}$ after the operation (recall).

Results: Eighteen patients (47.4\%) in Group A complained of cannula-induced pain compared with 35 (94.6\%) in Group $\mathrm{B}$ and $36(94.7 \%)$ in Group C $(\mathrm{P}<0.001)$. Group A patients showed significantly lower incidence of propofol-induced pain and recall of propofol-induced pain compared with Group $B(P<0.001$ and $P=0.01)$, whereas there was no difference compared with Group C.

Conclusions: Preoperative transdermal administration of 5\% lidocaine patch is an effective and simple method in reducing propofol-induced pain as well as cannula-induced pain.
\end{abstract}

Key Words: Cutaneous administration, Lidocaine, Pain, Propofol.

Corresponding author: Hyeon Jeong Lee, M.D., Ph.D.

Department of Anesthesia and Pain Medicine, Pusan National University Hospital, Medical Research Institute, Pusan National University School of Medicine, 179, Gudeok-ro, Seo-gu, Busan 49241, Korea

Tel: 82-51-240-7399, Fax: 82-51-242-7466

E-mail: lhjksk@pusan.ac.kr

Received: November 27, 2015.

Revised: February 17, 2016 (1st); April 28, 2016 (2nd); May 4, 2016 (3rd). Accepted: May 5, 2016.

Korean J Anesthesiol 2016 October 69(5): 468-473 http://dx.doi.org/10.4097/kjae.2016.69.5.468

\section{Introduction}

Topical analgesics have been proven efficacious and well tolerated with safety in several randomized clinical studies [1]. The lidocaine patch has a noninvasive drug delivery system for delivery of $5 \%$ lidocaine. Several studies have reported potential efficacy of $5 \%$ lidocaine patch in neuropathic and nonneuropathic pain condition [2-4], and our previous study demonstrated that pretreatment with the $5 \%$ lidocaine patch was effective in diminishing venipuncture induced pain, although rocuronium-related injection pain was not reduced in children [5].

(c) This is an open-access article distributed under the terms of the Creative Commons Attribution Non-Commercial License (http://creativecommons.org/ licenses/by-nc/4.0/), which permits unrestricted non-commercial use, distribution, and reproduction in any medium, provided the original work is properly cited. 
A number of clinical trials on propofol-induced pain have been conducted. Despite the popularity of propofol as an intravenous drug in general anesthesia or short-term sedation, the high incidence up to $65-87 \%$ of localized pain at the peripheral injection site of propofol has been a considerable problem of current clinical anesthesiology [6-8]. It is the clinical strategy of choice to add local anesthetics to cold propofol emulsion, preferably retaining both low- and medium-chain triglycerides, immediately before intravenous (IV) administration via central or a large bore peripheral vein [9]. Although, these methods reduce propofol-induced pain to some degree, the complexity and costs remain a problem. In addition, considering that most surgical patients are required to insert IV cannulation and experience pain during the injection of anesthetics or are afraid of the needlestick (have needle phobia), we could consider the clinical utility of topical anesthetics for prevention of propofol-induced pain as well as cannulation-induced pain in surgical patients.

Despite previous reports that $60 \%$ lidocaine tape may relieve pain on injection of propofol and venipuncture [7,10], 60\% lidocaine tape has a higher concentration than 5\% lidocaine patch and is not available in Korea. Our previous study demonstrated that a $5 \%$ lidocaine patch in pediatric surgical patients diminish venipuncture induced pain but was not effective in rocuronium induced pain [5]. The objective of this study was to determine whether preoperative transdermal treatment with a 5\% lidocaine patch could alleviate both propofol-induced pain and cannulainduced pain.

\section{Materials and Methods}

\section{Formulations}

The $5 \%$ lidocaine patch (Lidotop ${ }^{\circledR}$, SK chemicals, Seoul, Korea; Fig. 1), with a size of $10 \times 14 \mathrm{~cm}$, contains $700 \mathrm{mg}$ of lidocaine in an aqueous base.

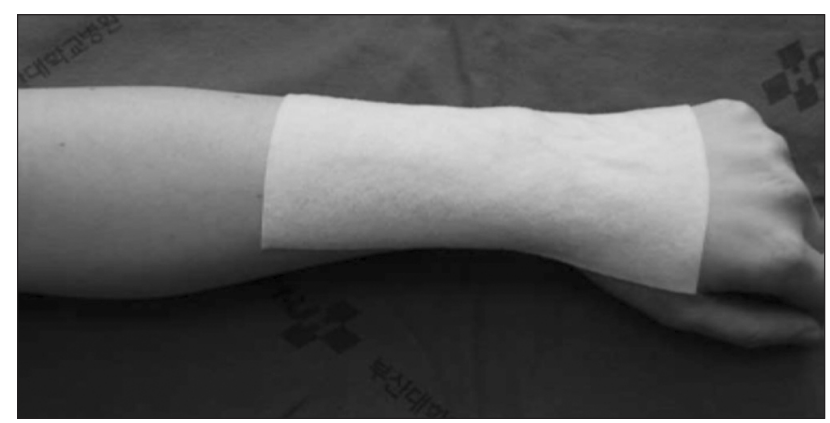

Fig. 1. The 5\% lidocaine patch was applied to the skin on the wrist of the nondominant hand. Thus, the entry point and final position of the tip of 20 -gauge cannula could be within the treated area by the $5 \%$ lidocaine patch.
Active lidocaine patch as prepared after removing the patch from its air tight pouch, peeling the release liner and the patch was applied to the skin on the wrist. For the placebo patch, the release liner was not removed and the patch was applied to the same site. Thus, the active patch and the placebo patch were identical in weight, shape, and color.

\section{Study design and patient selection}

A randomized, double-blind, placebo-controlled study was designed to evaluate the efficacy and safety of the $5 \%$ lidocaine patch for prevention of propofol-induced pain as well as cannula-induced pain in hospitalized surgical patients. This study was approved by the Institutional Review Board and conducted according to the Declaration of Helsinki. Informed consent was obtained from all patients prior to be enrolled in this study. A total of 126 American Society of Anesthesiologists physical status I and II patients aged 18-70 years presenting for elective surgery were allocated by sealed envelope including computer generated random numbers into three groups, as follows: pretreatment with a $5 \%$ lidocaine patch and premixed $2 \mathrm{ml}$ of normal saline with $1.5 \mathrm{mg} / \mathrm{kg}$ of $1 \%$ propofol (Group A); pretreatment with a placebo patch and premixed $2 \mathrm{ml}$ of normal saline with $1.5 \mathrm{mg} / \mathrm{kg}$ of $1 \%$ propofol (Group B); or pretreatment with a placebo patch and premixed $2 \mathrm{ml}$ of $2 \%$ lidocaine ( $40 \mathrm{mg}$ ) with $1.5 \mathrm{mg} / \mathrm{kg}$ of $1 \%$ propofol (Group C) for induction of anesthesia.

Exclusion criteria included (1) sensitivity to any of the active or inactive ingredients in the active or placebo patch; (2) injured skin at the designated patch site; or (3) prescription-strength analgesic medication usage during the $24 \mathrm{~h}$ period before the procedure.

Sample size was calculated as follows: the reported incidence of propofol-induced pain was $65-87 \%[2,3]$. Assuming at least $80 \%$ incidence in the control group, detection of a $40 \%$ reduction in the incidence would require at least 32 patients in each group to achieve $80 \%$ power at $5 \%$ Type I error. We enrolled more patients to compensate for possible exclusions.

\section{Conduct of anesthesia and assessment of pain}

After cleansing with an alcohol sponge, the patch was applied over a wide area of the nondominant hand and distal forearm $120 \mathrm{~min}$ prior to elective surgery in a $10 \times 14 \mathrm{~cm}$ width following allocation to the groups. During application of the patch, the investigator assessed the treatment area for erythema, edema, or adverse skin reactions.

None of the patients received premedication before the induction of anesthesia. When the patients arrived in the operating room, the patch was removed after marking the margin of the attached area of the patch by an anesthetic nurse. The an- 
esthesiologists who performed cannulation were not infomred whether a $5 \%$ lidocaine patch or placebo patch had been used. A 20 -gauge cannula was then inserted into an appropriate vein on the dorsum of the nondominant hand so that the catheter entry points were within the marked area and final tip positions were at the center of the marked area. We used a four point categorical verbal rating scale (VRS-4) with the words "no pain," "mild pain," "moderate pain," and "severe pain" $[7,11,12]$. Patients were asked to assess their pain by raiting their intensity of pain during insertion of the cannula. The propofol mixture was injected slowly with a 10 second pause between the administration of each quarter of the prepared mixed propofol with saline or 40 mg of lidocaine following, and the same anesthesiologists asked the patient to rate the severity of pain on the same scale as before. Anesthetic induction with propofol was continued until the remainder of the total calculated dose to be administered. When the sedation of the patient was not adequate, additional propofol was injected without lidocaine. Tracheal intubation was conducted with rocuronium $0.6 \mathrm{mg} / \mathrm{kg}$, and anesthesia was maintained with sevoflurane $1.0-3.0 \%$ and air $66 \%$ in oxygen, with controlled ventilation. At the end of anesthesia, the presence of emergence delirium was assessed by an investigator blinded to which drug had been administered.

Twenty-four hours after the operation, the recall of the intensity of propofol-induced pain and the injection site was checked for pain, edema, wheal, and flare response by the same investigator.

\section{Statistical analysis}

Statistical analysis was performed using Statview 5.0 (SAS Institute, Cary, NC, USA) and MedCalc ver. 11.2 (MedCalc Software, Mariakerke, Belgium). P values less than 0.05 were considered to be statistically significant. Data are presented as mean \pm standard deviation (SD) for continuous data and abso- lute frequencies (n), and percentages for frequency data.

Analysis of variance with Student-Newman Keuls post-hoc test was used for comparison of continuous parameters. The Kruskal-Wallis test with Dunn's post hoc test was used for analysis of pain scores and Fisher's exact test was used to compare the incidence of adverse events.

\section{Results}

A total of 126 patients were randomly allocated into three groups. Four patients in Group A, five patients in Group B, and four patients in Group $\mathrm{C}$ were excluded because of inappropriate application of active or placebo patch and failure in intravenous cannulation.

Thus, 113 patients were statistically analyzed. Demographic data were comparable among the groups (Table 1). Duration of surgery, duration of anesthesia, and time to recovery were also comparable. The mean doses of the propofol mixture administered for induction of anesthesia in Group A, B, and C were 11.4 $\pm 1.6,11.8 \pm 1.5$, and $11.5 \pm 1.9 \mathrm{ml}$, respectively. There were no significant differences among the groups in the amounts of propofol injected.

The incidence of cannulation induced pain was significantly reduced in Group A $(\mathrm{P}<0.01$; Table 2). The incidence of pain experienced during injection was also significantly reduced in Group A compared with Group B $(\mathrm{P}<0.01)$ and was similar in Group $C(P=0.33)$, and the incidence of recall of propofolinduced pain was remarkably lower in Group A than in Group B $(\mathrm{P}=0.01)$ and was similar in Group $\mathrm{C}(\mathrm{P}=0.63)$.

Although there was no significant difference, $10.5 \%$ of Group A patients experienced a burning sensation, and 7.9\% of Group $\mathrm{C}$ patients felt significant dizziness compared with patients in other groups ( $\mathrm{P}=0.048$, Table 3 ). No patient groups reported edema, wheal, or flare reaction at the injection site.

Table 1. Demographic Data

\begin{tabular}{|c|c|c|c|c|}
\hline & $\begin{array}{l}\text { Group A } \\
(\mathrm{N}=38)\end{array}$ & $\begin{array}{l}\text { Group B } \\
(\mathrm{N}=37)\end{array}$ & $\begin{array}{l}\text { Group C } \\
(\mathrm{N}=38)\end{array}$ & $\mathrm{P}$ \\
\hline Age (yr) & $39.3 \pm 14.4$ & $39.8 \pm 13.1$ & $36.4 \pm 12.8$ & 0.490 \\
\hline $\operatorname{Sex}(M / F)$ & $16 / 22$ & $19 / 18$ & $23 / 15$ & 0.275 \\
\hline Weight $(\mathrm{kg})$ & $65.1 \pm 9.9$ & $62.6 \pm 10.7$ & $63.1 \pm 12.5$ & 0.491 \\
\hline Height $(\mathrm{cm})$ & $166.8 \pm 8.0$ & $167.6 \pm 9.0$ & $164.5 \pm 8.3$ & 0.272 \\
\hline ASA & & & & 0.267 \\
\hline I & 24 & 18 & 25 & \\
\hline II & 14 & 19 & 13 & \\
\hline Given doses of propofol mixture $(\mathrm{ml})$ & $11.4 \pm 1.6$ & $11.8 \pm 1.5$ & $11.5 \pm 1.9$ & 0.528 \\
\hline
\end{tabular}

Values are expressed as means \pm SD or number (\%). Group A: pretreatment with $5 \%$ lidocaine patch and premix $2 \mathrm{ml}$ of normal saline with $1.5 \mathrm{mg} / \mathrm{kg}$ of $1 \%$ propofol, Group B: pretreatment with placebo patch and premix $2 \mathrm{ml}$ of normal saline with $1.5 \mathrm{mg} / \mathrm{kg}$ of $1 \%$ propofol, Group C: pretreatment with placebo patch and premix $2 \mathrm{ml}$ of $2 \%$ lidocaine ( $40 \mathrm{mg}$ ) with $1.5 \mathrm{mg} / \mathrm{kg}$ of $1 \%$ propofol. 
Table 2. Severity of Pain

\begin{tabular}{|c|c|c|c|c|c|c|c|}
\hline & \multirow{2}{*}{$\begin{array}{l}\text { Group A } \\
(\mathrm{N}=38)\end{array}$} & \multirow{2}{*}{$\begin{array}{l}\text { Group B } \\
(\mathrm{N}=37)\end{array}$} & \multirow{2}{*}{$\begin{array}{l}\text { Group C } \\
(\mathrm{N}=38)\end{array}$} & \multicolumn{4}{|c|}{$\mathrm{P}$} \\
\hline & & & & A-B-C & $A-B$ & B-C & C-A \\
\hline Cannula pain & & & & $<0.001$ & $<0.001$ & 0.983 & $<0.001$ \\
\hline None & $20(52.6)$ & $2(5.4)$ & $2(5.3)$ & & & & \\
\hline Mild & $10(26.3)$ & $20(54.1)$ & $19(50.0)$ & & & & \\
\hline Moderate & $8(21.1)$ & $11(29.7)$ & $12(31.6)$ & & & & \\
\hline Severe & 0 & $4(10.8)$ & $5(13.2)$ & & & & \\
\hline Injection pain & & & & $<0.001$ & $<0.001$ & $<0.001$ & 0.3271 \\
\hline None & $19(50.0)$ & $7(18.9)$ & $16(42.1)$ & & & & \\
\hline Mild & $11(28.9)$ & $5(13.5)$ & $17(44.7)$ & & & & \\
\hline Moderate & $8(21.1)$ & $19(51.4)$ & $5(13.2)$ & & & & \\
\hline Severe & $0(0)$ & $6(16.2)$ & $0(0)$ & & & & \\
\hline Recall of injection pain & & & & 0.01 & 0.0215 & 0.0248 & 0.6331 \\
\hline None & $23(60.5)$ & $14(37.8)$ & $19(50.0)$ & & & & \\
\hline Mild & $13(34.2)$ & $11(29.7)$ & $17(44.7)$ & & & & \\
\hline Moderate & $2(5.3)$ & $10(27.0)$ & $2(5.3)$ & & & & \\
\hline Severe & $0(0)$ & $2(5.4)$ & $0(0)$ & & & & \\
\hline
\end{tabular}

Values are expressed as number (\%). Group A: pretreatment with $5 \%$ lidocaine patch and premix $2 \mathrm{ml}$ of normal saline with $1.5 \mathrm{mg} / \mathrm{kg}$ of $1 \%$ propofol, Group B: pretreatment with placebo patch and premix $2 \mathrm{ml}$ of normal saline with $1.5 \mathrm{mg} / \mathrm{kg}$ of $1 \%$ propofol, Group C: pretreatment with placebo patch and premix $2 \mathrm{ml}$ of $2 \%$ lidocaine ( $40 \mathrm{mg}$ ) with $1.5 \mathrm{mg} / \mathrm{kg}$ of $1 \%$ propofol.

Table 3. Adverse Effects

\begin{tabular}{llccc}
\hline & $\begin{array}{l}\text { Group A } \\
(\mathrm{N}=38)\end{array}$ & $\begin{array}{l}\text { Group B } \\
(\mathrm{N}=37)\end{array}$ & $\begin{array}{l}\text { Group C } \\
(\mathrm{N}=38)\end{array}$ & $\mathrm{P}$ \\
\hline Burning sensation & $4(10.5)$ & $1(2.7)$ & $0(0.0)$ & 0.068 \\
Pruritus & $1(2.6)$ & $1(2.7)$ & $0(0.0)$ & 0.597 \\
Dizziness & $0(0)$ & $0(0)$ & $3(7.9)^{*}$ & 0.048 \\
\hline
\end{tabular}

Values are expressed as number (\%). Group A: pretreatment with $5 \%$ lidocaine patch and premix $2 \mathrm{ml}$ of normal saline with $1.5 \mathrm{mg} / \mathrm{kg}$ of $1 \%$ propofol, Group B: pretreatment with placebo patch and premix $2 \mathrm{ml}$ of normal saline with $1.5 \mathrm{mg} / \mathrm{kg}$ of $1 \%$ propofol, Group C: pretreatment with placebo patch and premix $2 \mathrm{ml}$ of $1 \%$ lidocaine $(40 \mathrm{mg}$ ) with $1.5 \mathrm{mg} / \mathrm{kg}$ of $1 \%$ propofol. * Means $\mathrm{P}<0.05$ compared with Group A and B.

\section{Discussion}

Our results showed that pretreatment with a $5 \%$ lidocaine patch reduced the incidence of propofol-induced pain as well as cannula-induced pain. We also demonstrated that a $5 \%$ lidocaine patch could be a safe and simple alternative for prophylaxis of propofol-induced pain without serious adverse events. Our results showed that the different application time for topical usage induced a better analgesic effect compared with a previous study [11]. Thus, application of a 5\% lidocaine patch 120 minutes before the use of propofol could be a useful alternative before the injection of propofol, even though we did not demonstrate the depth of penetration of lidocaine in our results.

Addition of 10-40 mg of lidocaine to propofol is common in routine clinical practice for propofol-induced pain. Lidocaine stabilizes the membrane, therefore, preventing vasospasm and dilation of the vein as a result of sympathetic nervous block. Although the resultant changes following the addition of lidocaine less than $20 \mathrm{mg}$ to $200 \mathrm{mg}$ of propofol are unlikely to be clinically important, the mixture is physiochemically unstable over time and may cause pulmonary embolism $[13,14]$.

Considering the possible risk of lidocaine mixing, application of topical anesthetics at the injection site before the injection of propofol could be a useful alternative. In addition, based on our results of adverse effects, the topical application of lidocaine reduced the incidence of patients discomfort such as dizziness followed by administration of propofol-lidocaine mixture.

McCluskey et al. [11] reported that patients treated with EMLA cream showed higher incidence (76\%) of propofolinduced pain than the lidocaine added group (37\%), although EMLA cream decrease the incidence of cannula induced pain (83\% in the untreated group vs. 50\% in the group treated with EMLA). In contrast, other investigators have reported that topical local anesthesia using 60\% lidocaine tape may remove the need for premixing of propofol with lidocaine, and the topical local anesthesia usage also has the dual benefit of diminishing 
pain caused by propofol and venipuncture $[7,10]$. Although the concentration of lidocaine tape and the method of injection of propofol was different, our results indicated that a 5\% lidocaine patch similarly reduced not only the incidence of cannula pain (44.4\% vs. $94.6 \%$ in Group B and $94.5 \%$ in Group C), but the incidence of propofol-induced pain ( $50 \%$ vs. $72.1 \%$ in Group B).

The possible reason for these contradictory results may be different application time of the topical local anesthetic. Previous investigators demonstrated that the application of topical anesthetics for more than 120 min could be acceptable for venous cannulation, as lidocaine penetrates more than $3 \mathrm{~mm}$ in depth after $120 \mathrm{~min}[15,16]$. Thus, we accepted $120 \mathrm{~min}$ of application time in this study, however, McCluskey et al. adopted $60 \mathrm{~min}$ of application time of topical anesthetics.

In our previous study, we demonstrated that the lidocaine patch in pediatric patients did not reduce the injection pain due to rocuronium. However, in this study we found that the lidocaine patch reduced the injection pain due to propofol. The reason for this different result may be different pain mechanism of two drugs. Up to date, the mechanisms of propofol-induced pain has not been fully demonstrated. However, the concentration of free drug within the aqueous phase of the emulsion [17] and activation of kinin cascade [18] is believed to be associated with propofol-induced pain. The mechanism of rocuronium induced pain remains unclear. Although it is associated with kinin cascade like propofol, the relatively low $\mathrm{pH}$ of the rocuronium solution is believed to be another primary pain mechanism [19]. Another reason for the different result may be different patient groups. The patients groups in this study were adults while the patients in the previous study were children. Therefore the difference of pain threshold and assessment tool may be associated with contradictory results.

Although the vein size was not measured in this study, the relationship between the diameter of the vein and the degree of pain need to be clarified. Moreover, the speed of injection of propofol also could be a causative factor for these contradictory results compared with previous studies.

The reported systemic absorption rate of lidocaine from the application of $5 \%$ lidocaine patches to the human skin is very low. The maximum concentration of plasma lidocaine is approximately $0.186 \mu \mathrm{g} / \mathrm{ml}$ after a $24 \mathrm{~h}$ application of 4 lidocaine patches, which is approximately $12-15 \%$ of the lidocaine concentration associated with cardiac side effect and $4-5 \%$ of that associated with systemic toxicity [20]. Thus, a 5\% lidocaine patch provides low risk of systemic adverse events and drugdrug interaction, despite of continuous application of up to four patches per day. In addition, the lidocaine patch is a singlelayer matrix patch which diffuses across the upper layers of the skin via passive diffusion from an area of high concentration to low concentration [21]. Following Weil et al. [22], the lidocaine patch may be cut to fit the patient size or the site of application without influencing the drug delivery system.

The most common adverse events generally involve mild skin reactions [23], although there was no serious clinical reaction on applied skin area in our study.

In Korea, $5 \%$ lidocaine patch (US \$1.38) is more expensive than $2 \%$ lidocaine (US $\$ 0.35$ for 1 vial). This may limit the widespread use of the lidocaine patch as a prophylactic application for propofol-induced pain as well as cannulation-induced pain. However, because most surgical patients fear the needlestick, the choice of proper technique in preventing propofol-induced pain as well as cannula-induced pain should not be based solely on the calculation of costs, but should also the preference of patients.

Tadicherla and Berman [24] suggested that an ideal topical anesthetic deliver leads to effective anesthesia within minutes when applied to intact skin, with long acting potentials and minimal side effects. Although Lidocaine patch could not have an effect within minutes, if we give some introduction about application of the lidocaine patch or if the patch could be applied in the admitting office, it leaves much room for consideration in the outpatient setting.

In our study, preoperative transdermal application of a 5\% lidocaine patch was a simple method that only required application for 120 minutes before anesthetic induction and it reduced the pain not only on injection of propofol, but also with cannulation, without serious side effect. Thus, it could be a novel, simple, safe and acceptable alternative method to reduce propofolinduced pain as well as cannula pain.

\section{Acknowledgments}

This work was supported by 2 year research grant from Pusan National University.

\section{References}

1. Sawynok J. Topical analgesics for neuropathic pain in the elderly: current and future prospects. Drugs Aging 2014; 31: 853-62.

2. Saber AA, Elgamal MH, Rao AJ, Itawi EA, Martinez RL. Early experience with lidocaine patch for postoperative pain control after laparoscopic ventral hernia repair. Int J Surg 2009; 7: 36-8.

3. Alvarez NA. Clarifying the use of lidoderm patch to treat pain associated with postherpetic neuralgia. Reg Anesth Pain Med 2004; $29: 75$. 
4. Katz NP, Gammaitoni AR, Davis MW, Dworkin RH. Lidocaine patch 5\% reduces pain intensity and interference with quality of life in patients with postherpetic neuralgia: an effectiveness trial. Pain Med 2002; 3: 324-32.

5. Kim CH, Yoon JU, Lee HJ, Shin SW, Yoon JY, Byeon GJ. Availability of a 5\% lidocaine patch used prophylactically for venipuncture- or injection-related pain in children. J Anesth 2012; 26: 552-5.

6. Macario A, Weinger M, Truong P, Lee M. Which clinical anesthesia outcomes are both common and important to avoid? The perspective of a panel of expert anesthesiologists. Anesth Analg 1999; 88: 1085-91.

7. Yokota S, Komatsu T, Komura Y, Nishiwaki K, Kimura T, Hosoda R, et al. Pretreatment with topical $60 \%$ lidocaine tape reduces pain on injection of propofol. Anesth Analg 1997; 85: 672-4.

8. Wilkinson D, Anderson M, Gauntlett IS. Pain on injection of propofol: modification by nitroglycerin. Anesth Analg 1993; 77: 1139-42.

9. Akeson J. Pain on injection of propofol - why bother? Acta Anaesthesiol Scand 2008; 52: 591-3.

10. Uda R, Ohtsuka M, Doi Y, Inamori K, Kunimasa K, Ohnaka M, et al. Sixty percent lidocaine tape alleviates pain on injection of propofol after diminishing venipuncture pain. Masui 1998; 47: 843-7.

11. McCluskey A, Currer BA, Sayeed I. The efficacy of 5\% lidocaine-prilocaine (EMLA) cream on pain during intravenous injection of propofol. Anesth Analg 2003; 97: 713-4.

12. Breivik H, Borchgrevink PC, Allen SM, Rosseland LA, Romundstad L, Hals EK, et al. Assessment of pain. Br J Anaesth 2008; 101: 17-24.

13. Lilley EM, Isert PR, Carasso ML, Kennedy RA. The effect of the addition of lignocaine on propofol emulsion stability. Anaesthesia 1996; 51: 815-8.

14. Masaki Y, Tanaka M, Nishikawa T. Physicochemical compatibility of propofol-lidocaine mixture. Anesth Analg 2003; 97: 1646-51.

15. Bjerring P, Arendt-Nielsen L. Depth and duration of skin analgesia to needle insertion after topical application of EMLA cream. Br J Anaesth 1990; 64: 173-7.

16. Wahlgren CF, Quiding H. Depth of cutaneous analgesia after application of a eutectic mixture of the local anesthetics lidocaine and prilocaine (EMLA cream). J Am Acad Dermatol 2000; 42: 584-8.

17. Doenicke AW, Roizen MF, Rau J, Kellermann W, Babl J. Reducing pain during propofol injection: the role of the solvent. Anesth Analg 1996; 82: $472-4$

18. Scott RP, Saunders DA, Norman J. Propofol: clinical strategies for preventing the pain of injection. Anaesthesia 1988; 43: 492-4.

19. Lockey D, Coleman P. Pain during injection of rocuronium bromide. Anaesthesia 1995; 50: 474.

20. Gammaitoni AR, Alvarez NA, Galer BS. Pharmacokinetics and safety of continuously applied lidocaine patches $5 \%$. Am J Health Syst Pharm 2002; 59: 2215-20.

21. Ko JC, Maxwell LK, Abbo LA, Weil AB. Pharmacokinetics of lidocaine following the application of 5\% lidocaine patches to cats. J Vet Pharmacol Ther 2008; 31: 359-67.

22. Weil AB, Ko J, Inoue T. The use of lidocaine patches. Compend Contin Educ Vet 2007; 29: 208-10, 212, 214-6.

23. Gammaitoni AR, Galer BS, Onawola R, Jensen MP, Argoff CE. Lidocaine patch 5\% and its positive impact on pain qualities in osteoarthritis: results of a pilot 2-week, open-label study using the Neuropathic Pain Scale. Curr Med Res Opin 2004; 20 Suppl 2: S13-9.

24. Tadicherla S, Berman B. Percutaneous dermal drug delivery for local pain control. Ther Clin Risk Manag 2006; 2: 99-113. 